\title{
Should fines depend on offenders' incomes? A questionnaire study on values and institutions
}

\author{
Kristof Bosmans $^{\mathrm{a}} \cdot$ Lucio Esposito $^{\mathrm{b}}$ \\ a Department of Economics, Maastricht University, \\ Tongersestraat 53, 6211 LM Maastricht, The Netherlands \\ E-mail: k.bosmans@maastrichtuniversity.nl \\ ${ }^{\mathrm{b}}$ Corresponding author. School of International Development, University of East Anglia, \\ NR4 7TJ, Norwich, United Kingdom
}

Email: lucio.esposito@uea.ac.uk

Tel: 0044(0)1603591882

\begin{abstract}
How to make sense of the cross-country heterogeneity in values emerging from international surveys? Our study suggests that the answer needs to go beyond a pure 'nurture' argument - adaptation to existing institutions and legal norms - and should tap into deeper preferences. In our case, Finnish respondents do support their country's system of income-dependent fines significantly more strongly than respondents living in countries using a fixed fines system. However, they also hold different beliefs on the relationship between income and well-being (utility) and hence on the burdens imposed by fining offenders at different income levels. A further illustration of our argument is provided in the context of income taxation.
\end{abstract}

Keywords. Fine systems, Taxation, Vertical equity, Equal sacrifice, Institutions, Cross-country studies

JEL Classifications. D63, H26, H29, K42 


\section{Introduction}

Questionnaire studies have revealed considerable cross-country differences in normative judgments expressed by respondents. ${ }^{1}$ This raises the question of what brings about these differences. Do expressed normative judgments merely reflect institutional differences between countries, with citizens adapting their values to the particular legal rules of their country? Or, instead, do these judgments reflect genuine cross-country differences in normative preferences? If the latter is true, then one may even hypothesize that differences in these deeper preferences are among the causes of institutional differences. ${ }^{2}$

We use a questionnaire approach to study cross-country differences in normative judgments. In order to address the above questions, we need to consider a case for which there are clear-cut institutional differences between countries. We therefore focus on systems of fines for minor offences. In most countries the monetary amounts of such fines depend only on the gravity of the offence. Finland is exceptional, as it uses a fine system in which additionally the amount of the fine increases with the personal income of the offender. This system of 'unit fines' or 'day fines' has been in place in Finland since 1921. The news frequently reports on the more spectacular real-world outcomes of the unit fine system - e.g., the case of Mr. Jussi Salonoja, who received a fine of 170,000 euros for driving $80 \mathrm{~km} / \mathrm{h}$ in a $40 \mathrm{~km} / \mathrm{h}$ zone in Helsinki in $2003 .^{3}$ The typical justification of the unit fine system builds upon the idea of vertical equity ("calling for an appropriate differentiation among unequals", Musgrave, 1990, p. 113) and is intimately connected to the notion of equal sacrifice in income taxation (see, inter alia, Young, 1990). Indeed, given decreasing marginal utility of income, fines of equal amounts for offenders with different incomes would result in unequal utility burdens. For a comprehensive philosophical analysis of this point, see Eriksson and Goodin (2007).

We will focus on two questions. The first question is whether Finnish citizens have different normative judgments with respect to fines from citizens of other countries - in our case Italy, Mozambique and South Africa. Our hypothesis is that citizens do indeed support to a considerable extent the actual fine system of their country. The second question is whether this support points merely to an adaptation of individual values to the actual fine

\footnotetext{
${ }^{1}$ See, e.g., Amiel, Cowell and Gaertner (2009), Beckman, Formby, Smith and Zheng (2002), Gaertner and Jungeilges (2002), Gaertner, Jungeilges and Neck (2001), Gaertner and Schwettmann (2007), Schokkaert and Devooght (2003), Corazzini, Esposito and Majorano (2012). See Gaertner and Schokkaert (2012) and Konow (2003) for surveys of the literature.

2 The relationship between values and institutions is complex, with causality potentially running in both directions (see, e.g., the equilibrium analysis of Alesina and Angeletos, 2005).

${ }^{3}$ See http://news.bbc.co.uk/1/hi/business/3477285.stm (consulted on July 4th, 2013).
} 
system in place, or, on the contrary, whether it reflects deeper normative preferences that are independent of real-world institutions. This question is a priori open and constitutes our main research subject.

The paper develops as follows. The next section describes our questionnaire set-up and the data collection strategy. Section 3 presents and discusses our main results. A further illustration in the context of income taxation is presented in Section 4. Section 5 concludes.

\section{Questionnaire set-up}

The questionnaire survey was conducted among 1,506 university students in four countries: Finland (University of Helsinki), Italy (University of Milan and University of Pavia), Mozambique (University Eduardo Mondlane) and South Africa (University of Johannesburg). The anonymous questionnaires were run personally by the authors during supervised classroom sessions. ${ }^{4}$ Respondents were presented with the questionnaire in their own native language - the English, Finnish, Italian and Portuguese versions were carefully produced and checked by back-translations. Pilot tests led to several improvements of the text.

While Finland uses unit fines for minor offences, in Italy, Mozambique and South Africa such fines consist of a fixed amount independent from the offender's income. The questionnaire has two main objectives. The first objective is to elicit judgments on which of the two alternative fine systems would be considered as fair. Here, the hypothesis is that respondents from Finland are different from those in the other three countries in that they would exhibit a stronger support for a unit fine system. The second objective of the questionnaire is to elicit opinions on the relationship between income and well-being (utility). While this relationship is closely related to attitudes towards fines (the more concave the utility function, the greater the utility loss caused by a fixed fine for a lower income individual as compared to a higher income individual), it is at the same time unrelated to existing institutions. If Finnish respondents are also different with respect to these opinions on wellbeing, then it would be difficult to ascribe the heterogeneity in judgments on fine systems merely to adaptation to existing real-world institutions.

The questionnaire, which is given in full in Appendix 1, consists of three parts - A, B and C. We first discuss Part B, which consists of two questions exploring respondents'

\footnotetext{
${ }^{4}$ The questionnaire completion took place during either the first or the last twenty minutes of a lecture. In the latter case we followed up several students to ask them about the questionnaire they had just filled in. They appeared to have fully understood the situations depicted and the questions raised in the questionnaire.
} 
attitudes toward fines. Respondents are invited to imagine themselves in charge of setting up a fine system that they consider to be fair. Question 1 is about the justification for imposing fines and may help to invoke a normative mindset. ${ }^{5}$ Question 2 tackles directly our first research question, inviting our respondents to express their view on what should be the relationship between fine amount and offender's income. The question, which puts a simple case to the respondents and asks explicitly for a normative response, is formulated as follows:

Alan earns 3,600 Rand per month. He has to pay a fine of 360 Rand for speeding. Bill earns 1,800 Rand per month and has driven equally fast as Alan. What fine for Bill would your regulation establish?

(a) A fine equal to 360 Rand.

(b) A fine lower than 360 Rand. I would say ......... (please indicate).

(c) A fine larger than 360 Rand. I would say ........ (please indicate).

It is clear that response (a) is consistent with a system based on fixed fines, while response (b) is consistent with a unit fine system. Note that the amounts given above, as well as in the rest of this section, are those appearing in the South African version of the questionnaire. In the actual questionnaires handed out to the respondents, different amounts were used for each country, taking into account differences in currencies and in purchasing power. ${ }^{6}$

Part A of the questionnaire deals with opinions concerning the relationship between income and well-being. The question is formulated as follows:

Adam, Bob, Chris, Dan and Edward are individuals identical in everything other than their monthly incomes. Adam earns 3,600 Rand. Due to some circumstance, he loses 360 Rand. This loss of money obviously causes Adam's well-being to decrease. What amount of money would Bob, Chris, Dan and Edward have to lose to incur the same reduction in well-being as Adam?

Bob, who earns 1,800 Rand:

$\begin{array}{cccccc}\square 18 & \square 90 & \square 162 & \square 720 & \square 1,440 & \square \text { other amount : } \\ \square 36 & \square 108 & \square 180 & \square 900 & \square 1,620 & \\ \square 54 & \square 126 & \square 360 & \square 1,080 & \square 1,800 & \ldots \ldots \ldots \\ \square 72 & \square 144 & \square 540 & \square 1,260 & \square 2,700 & \end{array}$

\footnotetext{
${ }^{5}$ Question 1, given in full in Appendix 1, gives a choice between two possible justifications for fines: punishment or deterrence. Punishment was chosen as a justification by $25 \%$ of the respondents in Finland, 33\% in Italy, 28\% in Mozambique and 45\% in South Africa (in each case the rest of the respondents chose deterrence). Responses to Question 1 turned out to be unrelated to the issues of interest in this paper and will therefore not be discussed any further.

${ }^{6}$ To correct for differences in purchasing power, we used amounts in the questionnaires which are the same percentage of each country's GNI.
} 
The same table is presented for three additional cases: for "Chris, who earns 900 Rand", "Dan, who earns 9,000 Rand" and "Edward, who earns 18,000 Rand". Writing well-being, or utility, as a function $U$ of income, this question can be formalized as asking respondents to choose the amount $\ell$ such that

$$
U(3,600)-U(3,600-360)=U(y)-U(y-\ell),
$$

where $y$ is the income of Bob, Chris, Dan or Edward, depending on the question. In the case of Bob, the loss $\ell$ that solves the equation varies conversely with the degree of concavity of $U$. For instance, with a linear utility function we have $\ell=360$, while with a logarithmic utility function (a particular concave utility function) we have $\ell=180$. Also in the case of Chris the loss $\ell$ is conversely related to the degree of concavity of the utility function. Because Dan and Edward earn more than Adam's reference income of 3,600, in these cases the relationship between the loss chosen and the degree of concavity of the utility function is positive.

Part A is closely related to Question 2 in Part B. One could say that the question in Part A provides a positive informational basis for the normative Question 2 in Part B. That is, the more concave the relationship between income and well-being, the more a fixed fine asymmetrically punishes a person with a relatively lower income in comparison to a person with a relatively higher income. So one would expect there to be a positive relation between the degree of concavity expressed in Part A and the support for unit fines in Part B. In Section 3 we provide empirical evidence that supports this claim (see the discussion of specification 2 in Table 3). Now, it is clear that Part A is, unlike Part B, unrelated to existing institutions. This will allow us to check whether differences in opinions concerning the relation between income and well-being offer a possible explanation of differences in attitudes toward fines. Part A was presented to the respondents before Part B in order to avoid the responses of Part A to be contaminated by thinking about existing institutions.

Part $\mathrm{C}$ of the questionnaire includes questions on personal characteristics and family circumstances. A second version of the questionnaire was also distributed, which was identical for Parts A and C, but replaced Part B by questions about taxes. This version is discussed in Section 4. Table 1 gives an overview of the sample characteristics across the four countries. ${ }^{7}$

\footnotetext{
${ }^{7}$ For Italy, the total sample size is 607 , while the fine version and tax version sample sizes add up to only 360 . The remaining 247 respondents filled out a variant of the fine version questionnaire, which was identical for Parts A and C, but different for Question 2 of Part B (with different numbers, or the brief additional statement
} 


\section{[Table 1 about here]}

\section{[Table 2 about here]}

\section{Results}

Our first question is whether respondents' attitudes towards fines reflect the actual fine system of the country they live in. Table 2 presents the results of Question 2 of Part B of the questionnaire. In each country, the two solutions selected most frequently by the respondents are equality of absolute fines (180 Rand in the South African version) and equality of fines in proportion to income (360 Rand). There are, however, considerable differences across the four countries. For Finland (FI), the proportional solution is substantially more popular than the absolute solution. Responses thus clearly support the unit fine system actually in place in Finland. For Italy (IT) and South Africa (ZA), the absolute solution beats the proportional solution. Again, this is in line with the actual fine systems in those countries. The results for Mozambique (MZ), where citizen are rarely ever confronted with fines for speeding, are in between. Specification 1 in Table 3 shows that the differences in response patterns across countries are significant after a number of control variables are included in the regression. ${ }^{8}$ In sum, we find a clear relationship between attitudes toward fines and existing real-world institutions.

\section{[Table 3 about here]}

The second issue is now whether these differences across countries are merely a consequence of differences between institutions, or whether they may reflect deeper differences in respondents' views concerning the relationship between income and well-being. To tackle this issue, we consider Part A of the questionnaire. The results are presented in Tables $4 \mathrm{a}-4 \mathrm{~d}$.

For Italy, Mozambique and South Africa, proportional answers prevail in all four cases, a pattern in line with a logarithmic utility function. Finland consistently deviates from

\footnotetext{
that the money collected through the imposition of the fines would be used to fund school and hospitals). The variants did not yield significant changes in the responses. We will only use the results for Parts $\mathrm{A}$ and $\mathrm{C}$ of these variants (see Tables $4 \mathrm{a}-4 \mathrm{~d}$ and 5).

${ }^{8}$ The specifications in Table 3 do not include all variables obtained in Part $\mathrm{C}$ of the questionnaire. The omitted variables were rarely significant in the alternative specifications we tried. Leaving them out does not qualitatively change the results pertaining to the variables of main interest.
} 
this pattern. At lower incomes (Tables 4a and 4b), a substantial share of the respondents chooses amounts lower than the proportional amounts, while at higher incomes (Tables 4c and 4d) a substantial share chooses amounts higher than the proportional amounts. ${ }^{9}$ Overall, Finnish responses are in line with a utility function with a higher degree of concavity than the logarithmic one, with lower incomes more affected by a given income loss and higher incomes less affected. Table 5 shows that also in this case these differences across countries are significant controlling for a number of variables.

The stronger concavity found for the Finnish respondents suggests that they see a fixed income loss as more unequally affecting lower incomes than respondents in the other three countries. This is one possible explanation of why Finnish respondents may believe that a fine that depends on income is normatively desirable. Specification 2 in Table 3 shows that there is indeed a clear connection between answers to the Bob question in Part A (Table 4a) and the fine question in Part B. Students responding in line with a greater concavity in the former also choose a lower fine in the latter — the 'Proportional for Bob' and 'More than proportional for Bob' variables are strongly significant.

We conclude that there are genuine differences in preferences between the Finnish respondents and the respondents of the other three countries, which strongly suggests that differing attitudes towards fines do not merely reflect differences in existing institutions.

[Table 4a about here]

[Table $4 b$ about here]

[Table 4c about here]

[Table 4d about here]

[Table 5 about here]

\footnotetext{
${ }^{9}$ We do not report the answers to the Edward question for Mozambique in Table 4d (nor use them in Table 5). The reason is that these results were likely significantly affected by a misprint in the question. The income of Edward is 3,550 MZN in the Mozambican questionnaire. By mistake, the proportional amount 355 MZN was not offered among the choice options. A substantial $48 \%$ of the respondents added $355 \mathrm{MZN}$ themselves and $20 \%$ chose $350 \mathrm{MZN}$, the available option nearest to the proportional solution. Note that, under the assumption that these $20 \%$ also actually prefer the proportional solution, the results are in line with the other results reported.
} 


\section{[Table 6 about here]}

\section{A further illustration on income taxation}

We look now at the case of personal income taxation, a further normative issue for which the information elicited in Part A may constitute an informational basis. There is not such a striking difference between income tax systems of Finland and those of the other countries in our sample as there is for fines. However, given the differences in the responses to Part A, the question arises whether the Finnish respondents are also different with respect to attitudes to taxation.

We consider a question similar to that about fines (Part B, Question 2), but framed in the context of taxes. In the taxation version of the questionnaire (see Appendix 2), Question 2 in Part B was formulated as follows:

Alan earns 3,600 Rand and has to pay a tax of 360 Rand. Bill earns 1,800 Rand. What tax for Bill would your tax scheme establish?

(a) A tax equal to 360 Rand.

(b) A tax lower than 360 Rand. I would say ......... (please indicate).

(c) A tax larger than 360 Rand. I would say ......... (please indicate).

As Table 6 shows, Finnish respondents are different again. While proportional tax rates are most popular in Italy, Mozambique and South Africa, Finnish respondents prefer to tax the poorer individual at a lower tax rate. These cross-country differences in responses are in line with the results of Part A of the questionnaire, already reported in Section 3. Specification 1 in Table 7 shows that differences across countries are significant after a number of control variables are taken into account. Specification 2 shows that there is a clear connection between respondents' answers for Part A and Part B - as is the case for Table 3, the 'Proportional for Bob' and 'More than proportional for Bob' variables are strongly significant. We see these results as strengthening our previous conclusions.

[Table 7 about here] 


\section{Conclusion}

Internationally comparative survey work on values suggests a correlation between value judgements revealed by respondents and specific country institutions. This is not surprising, but it raises the question of how to interpret these differences in responses. Do they simply reflect differences in institutions (with respondents adapting their attitudes to the prevailing legal rules), or do they reflect deeper differences in preferences? In the latter case, one could even formulate the hypothesis that these primitive differences in preferences are part of the explanation of the institutional differences.

In order to shed light on these questions, we carried out a questionnaire survey tackling a case of clear-cut differences in institutions between countries. We focused on the case of fine systems, where the so-called 'unit' or 'day' fines in which the fine amount depends on the offender's income level is in sharp contrast to the more widely spread system in which fine amounts depend only on the type of offence. The results of our questionnaire strongly suggest that respondents' normative judgments are not mere adaptations to the particular characteristics of the institutions of their country. Indeed, we found that these value judgments correlate with cross-country differences in deeper preferences that are independent of existing institutions. A new question is then triggered, namely where these differences in preferences originate. An array of cultural, political or historical factors is plausibly relevant in answering this question. Further research is necessary to explore this fascinating issue.

\section{References}

Alesina A and G-M Angeletos, 2005. Fairness and redistribution. American Economic Review 95, 960-980.

Amiel Y, FA Cowell and W Gaertner, 2009. To be or not to be involved: a questionnaireexperimental view on Harsanyi's utilitarian ethics. Social Choice and Welfare 32, 299316.

Beckman SR, JP Formby, WJ Smith and B Zheng, 2002. Envy, malice and Pareto efficiency: an experimental examination. Social Choice and Welfare 19, 349-367. 
Corazzini L, L Esposito and F Majorano, 2012. Reign in hell or serve in heaven? A crosscountry journey into the relative vs absolute perceptions of wellbeing. Journal of Economic Behavior \& Organization 81, 715-730.

Eriksson L and RE Goodin, 2007. The measuring rod of time: the example of Swedish dayfines. Journal of Applied Philosophy 24, 125-136.

Gaertner W and J Jungeilges, 2002. Evaluation via extended orderings: empirical findings from Western and Eastern Europe. Social Choice and Welfare 19, 29-55.

Gaertner W, J Jungeilges and R Neck, 2001. Cross-cultural equity evaluations: a questionnaire-experimental approach. European Economic Review 45, 953-963.

Gaertner W and E Schokkaert, 2012. Empirical Social Choice. Cambridge: Cambridge University Press.

Gaertner W and L Schwettmann, 2007. Equity, responsibility and the cultural dimension. Economica 74, 627-649.

Konow J, 2003. Which is the fairest one of all? A positive analysis of justice theories. Journal of Economic Literature 41, 1188-1239.

Musgrave RA, 1990. Horizontal equity, once more. National Tax Journal 43, 113-122.

Schokkaert E and K Devooght, 2003. Responsibility-sensitive fair compensation in different cultures. Social Choice and Welfare 21, 207-242.

Young HP, 1990. Progressive taxation and equal sacrifice. American Economic Review 80, 253-266. 
Table 1. Sample characteristics

\begin{tabular}{lcccc}
\hline & Finland & Italy & Mozambique & South Africa \\
\hline Total sample size & 132 & 607 & 251 & 516 \\
\hline Fine version sample size & 65 & 202 & 128 & 259 \\
Average age & 24 & 21 & 25 & 20 \\
Male (\%) & 58 & 28 & 49 & 32 \\
Economics studies (\%) & 100 & 40 & 50 & 49 \\
Educational studies (\%) & 0 & 38 & 50 & 51 \\
Political studies (\%) & 0 & 22 & 0 & 0 \\
Tax version sample size & 67 & 158 & 123 & 257 \\
Average age & 26 & 21 & 26 & 20 \\
Male (\%) & 63 & 32 & 64 & 33 \\
Economics studies (\%) & 100 & 51 & 45 & 48 \\
Educational studies (\%) & 0 & 49 & 55 & 52 \\
Political studies (\%) & 0 & 0 & 0 & 0 \\
\hline
\end{tabular}

Table 2. Responses to Question 2 in Part B (in \%)

"What fine $x$ should someone earning 1,800 pay, given that someone earning 3,600 has to pay 360 ?"

\begin{tabular}{ccccc}
\hline Response & FI $(n=64)$ & IT $(n=199)$ & $\mathrm{MZ}(n=118)$ & ZA $(n=230)$ \\
\hline$x<180$ & 9 & 4 & 10 & 2 \\
$x=180$ (proportional) & 58 & 20 & 40 & 24 \\
$180<x<360$ & 8 & 3 & 6 & 2 \\
$x=360$ (absolute) & 22 & 71 & 42 & 72 \\
$x>360$ & 3 & 2 & 2 & 0 \\
\hline
\end{tabular}


Table 3. Ordered probit regressions, coefficient (standard error)

\begin{tabular}{|c|c|c|}
\hline Variable & Specification 1 & Specification 2 \\
\hline Proportional for Bob & - & $\begin{array}{l}0.477 * * * \\
(0.143)\end{array}$ \\
\hline More than proportional for Bob & - & $\begin{array}{l}0.784 * * * \\
(0.206)\end{array}$ \\
\hline Age & $\begin{array}{l}-0.014 \\
(0.012)\end{array}$ & $\begin{array}{l}-0.017 \\
(0.012)\end{array}$ \\
\hline Male & $\begin{array}{l}-0.012 \\
(0.109)\end{array}$ & $\begin{array}{c}0.012 \\
(0.110)\end{array}$ \\
\hline Economics & $\begin{array}{l}0.040 \\
(0.114)\end{array}$ & $\begin{array}{c}0.064 \\
(0.115)\end{array}$ \\
\hline Politics & $\begin{array}{l}0.559 * * \\
(0.235)\end{array}$ & $\begin{array}{l}0.599 * * \\
(0.240)\end{array}$ \\
\hline Lower relative living standard & $\begin{array}{c}0.421 \\
(0.262)\end{array}$ & $\begin{array}{c}0.349 \\
(0.265)\end{array}$ \\
\hline Average relative living standard & $\begin{array}{l}0.550 * * \\
(0.239)\end{array}$ & $\begin{array}{l}0.489 * * \\
(0.241)\end{array}$ \\
\hline Higher relative living standard & $\begin{array}{l}0.627 * * \\
(0.261)\end{array}$ & $\begin{array}{l}0.592 * * \\
(0.263)\end{array}$ \\
\hline $\begin{array}{c}\text { Very much higher relative living } \\
\text { standard }\end{array}$ & $\begin{array}{c}0.387 \\
(0.437)\end{array}$ & $\begin{array}{l}0.285 \\
(0.439)\end{array}$ \\
\hline Fine as punishment & $\begin{array}{c}0.084 \\
(0.104)\end{array}$ & $\begin{array}{c}0.096 \\
(0.106)\end{array}$ \\
\hline Italy & $\begin{array}{l}0.782^{* * * *} \\
(0.186)\end{array}$ & $\begin{array}{l}0.579 * * * \\
(0.193)\end{array}$ \\
\hline Mozambique & $\begin{array}{c}0.320^{*} \\
(0.187)\end{array}$ & $\begin{array}{l}0.156 \\
(0.192)\end{array}$ \\
\hline South Africa & $\begin{array}{l}0.803 * * * \\
(0.183)\end{array}$ & $\begin{array}{l}0.629 * * * \\
(0.191)\end{array}$ \\
\hline
\end{tabular}

The dependent variable takes the value 1 if the response to Question 2 in Part B was less than proportional, 2 if proportional, 3 if between proportional and absolute, 4 if absolute and 5 if more than absolute. 'Proportional for Bob'/'More than proportional for Bob' takes the vale 1 if the response to the Bob question in Part A was proportional/more than proportional and 0 otherwise. 'Age' is the respondent's age in years. 'Male' takes the value 1 if the respondent is male and 0 otherwise. 'Economics'/'Politics' takes the value 1 if the respondent's study discipline is economics/politic and 0 otherwise. 'Lower/average/higher/very much higher relative living standard' takes the value 1 if the corresponding response is given in question 5 of Part $\mathrm{C}$ and 0 otherwise. 'Fine as punishment' takes the value 1 if the response to Question 1 in Part B was "Punishment" and 0 otherwise. 'Italy'/'Mozambique'/'South Africa' takes the value 1 if the respondent belongs to the Italian/Mozambican/South African sample and 0 otherwise. Significance at the 10\%, 5\% and $1 \%$ level is denoted by $* * *$ and $* * *$, respectively. 
Table 4a. Responses for the 'Bob' case in Part A (in \%)

"What money loss $x$ for someone earning 1,800 causes the same loss in well-being as a loss of 360 for someone earning 3,600?"

\begin{tabular}{ccccc}
\hline Response & FI $(n=132)$ & IT $(n=603)$ & MZ $(n=244)$ & ZA $(n=507)$ \\
\hline$x<180$ & 46 & 10 & 22 & 10 \\
$x=180$ (proportional) & 52 & 81 & 66 & 78 \\
$180<x<360$ & 2 & 0 & 0 & 0 \\
$x=360$ (absolute) & 1 & 3 & 2 & 4 \\
$x>360$ & 0 & 6 & 11 & 9 \\
\hline
\end{tabular}

Table 4b. Responses for the 'Chris' case in Part A (in \%)

"What money loss $x$ for someone earning 900 causes the same loss in well-being as a loss of 360 for someone earning 3,600?"

\begin{tabular}{ccccc}
\hline Response & FI $(n=132)$ & IT $(n=604)$ & MZ $(n=243)$ & ZA $(n=507)$ \\
\hline$x<90$ & 46 & 12 & 17 & 6 \\
$x=90$ (proportional) & 52 & 76 & 68 & 80 \\
$90<x<360$ & 1 & 5 & 2 & 3 \\
$x=360$ (absolute) & 1 & 3 & 3 & 3 \\
$x>360$ & 1 & 5 & 11 & 8 \\
\hline
\end{tabular}


Table 4c. Responses for the 'Dan' case in Part A (in \%)

"What money loss $x$ for someone earning 9,000 causes the same loss in well-being as a loss of 360 for someone earning 3,600?"

\begin{tabular}{ccccc}
\hline Response & FI $(n=132)$ & IT $(n=603)$ & MZ $(n=244)$ & ZA $(n=506)$ \\
\hline$x<360$ & 0 & 3 & 12 & 4 \\
$x=360$ (absolute) & 1 & 1 & 3 & 3 \\
$360<x<900$ & 2 & 3 & 4 & 3 \\
$x=900$ (proportional) & 49 & 74 & 68 & 79 \\
$x>900$ & 49 & 19 & 13 & 11 \\
\hline
\end{tabular}

Table 4d. Responses for the 'Edward' case in Part A (in \%)

"What money loss $x$ for someone earning 18,000 causes the same loss in well-being as a loss of 360 for someone earning 3,600 ?"

\begin{tabular}{ccccc}
\hline Response & FI $(n=132)$ & IT $(n=601)$ & MZ & ZA $(n=505)$ \\
\hline$x<360$ & 1 & 12 & - & 6 \\
$x=360$ (absolute) & 1 & 1 & - & 2 \\
$360<x<1,800$ & 2 & 4 & - & 6 \\
$x=1,800$ (proportional) & 49 & 75 & - & 77 \\
$x>1,800$ & 47 & 18 & - & 9 \\
\hline
\end{tabular}


Table 5. Ordered probit regressions, coefficient (standard error)

\begin{tabular}{cllll}
\hline Variable & Bob & Chris & Dan & Edward \\
\hline Age & -0.008 & -0.010 & -0.001 & 0.004 \\
& $(0.008)$ & $(0.008)$ & $(0.008)$ & $(0.012)$ \\
Male & -0.084 & -0.094 & $0.231^{* * *}$ & $0.238^{* * *}$ \\
& $(0.071)$ & $(0.070)$ & $(0.070)$ & $(0.078)$ \\
Economics & -0.090 & $-0.177 * *$ & $-0.154 * *$ & -0.116 \\
& $(0.076)$ & $(0.075)$ & $(0.075)$ & $(0.085)$ \\
Politics & 0.010 & 0.003 & $-0.432^{* * *}$ & $-0.338^{* *}$ \\
& $(0.135)$ & $(0.133)$ & $(0.133)$ & $(0.136)$ \\
Italy & $0.920 * * *$ & $0.927 * * *$ & $-0.682^{* * *}$ & $-0.647 * * *$ \\
& $(0.131)$ & $(0.130)$ & $(0.129)$ & $(0.133)$ \\
Mozambique & $0.776 * * *$ & $0.934 * * *$ & $-1.271 * * *$ & - \\
& $(0.140)$ & $(0.140)$ & $(0.141)$ & \\
South Africa & $1.025^{* * *}$ & $1.083^{* * *}$ & $-1.064 * * *$ & $-1.164 * * *$ \\
& $(0.137)$ & $(0.136)$ & $(0.136)$ & $(0.143)$ \\
\hline
\end{tabular}

The dependent variable takes values 1 if the answer to the Bob/Chris/Dan/Edward question in Part A was less than proportional, 2 if proportional and 3 if more than proportional. See Table 3 for the definitions of the remaining variables. Significance at the $10 \%, 5 \%$ and $1 \%$ level is denoted by $* * *$ and $* * *$, respectively.

Table 6. Responses to Question 2 in Part B (tax version) (in \%)

"What tax $x$ should someone earning 1,800 pay, given that someone earning 3,600 has to pay 360 ?"

\begin{tabular}{ccccc}
\hline Response & FI $(n=67)$ & IT $(n=152)$ & MZ $(n=114)$ & ZA $(n=205)$ \\
\hline$x<180$ & 63 & 18 & 21 & 12 \\
$x=180$ (proportional) & 30 & 76 & 63 & 73 \\
$180<x<360$ & 3 & 1 & 5 & 3 \\
$x=360$ (absolute) & 5 & 5 & 10 & 12 \\
$x>360$ & 0 & 0 & 1 & 1 \\
\hline
\end{tabular}


Table 7. Ordered probit regressions, coefficient (standard error)

\begin{tabular}{|c|c|c|}
\hline Variable & Specification 1 & Specification 2 \\
\hline Proportional for Bob & - & $\begin{array}{l}1.081^{* * *} \\
(0.162)\end{array}$ \\
\hline More than proportional for Bob & - & $\begin{array}{l}1.508^{* * *} \\
(0.245)\end{array}$ \\
\hline Age & $\begin{array}{l}-0.006 \\
(0.012)\end{array}$ & $\begin{array}{l}-0.005 \\
(0.012)\end{array}$ \\
\hline Male & $\begin{array}{l}-0.239 * * \\
(0.120)\end{array}$ & $\begin{array}{l}-0.226^{*} \\
(0.124)\end{array}$ \\
\hline Economics & $\begin{array}{l}-0.099 \\
(0.119)\end{array}$ & $\begin{array}{l}-0.174 \\
(0.124)\end{array}$ \\
\hline Lower relative living standard & $\begin{array}{l}-0.333 \\
(0.331)\end{array}$ & $\begin{array}{l}-0.453 \\
(0.359)\end{array}$ \\
\hline Average relative living standard & $\begin{array}{l}-0.294 \\
(0.313)\end{array}$ & $\begin{array}{l}-0.391 \\
(0.341)\end{array}$ \\
\hline Higher relative living standard & $\begin{array}{l}-0.352 \\
(0.334)\end{array}$ & $\begin{array}{l}-0.500 \\
(0.363)\end{array}$ \\
\hline $\begin{array}{l}\text { Very much higher relative living } \\
\text { standard }\end{array}$ & $\begin{array}{l}-0.677 \\
(0.439)\end{array}$ & $\begin{array}{l}-0.786^{*} \\
(0.470)\end{array}$ \\
\hline Largely public provision & $\begin{array}{l}-0.411 \\
(0.138)\end{array}$ & $\begin{array}{l}-0.039 \\
(0.143)\end{array}$ \\
\hline Largely private provision & $\begin{array}{c}0.121 \\
(0.177)\end{array}$ & $\begin{array}{l}0.088 \\
(0.183)\end{array}$ \\
\hline Entirely private provision & $\begin{array}{c}0.342 \\
(0.424)\end{array}$ & $\begin{array}{c}0.447 \\
(0.430)\end{array}$ \\
\hline Italy & $\begin{array}{l}0.755^{* * *} \\
(0.203)\end{array}$ & $\begin{array}{l}0.474 * * \\
(0.216)\end{array}$ \\
\hline Mozambique & $\begin{array}{l}1.003 * * * \\
(0.203)\end{array}$ & $\begin{array}{l}0.872 * * * \\
(0.215)\end{array}$ \\
\hline South Africa & $\begin{array}{l}1.085 * * * \\
(0.208)\end{array}$ & $\begin{array}{l}0.784 * * * \\
(0.221)\end{array}$ \\
\hline
\end{tabular}

The dependent variable takes values 1 if the answer to Question 2 in Part B (tax version) was less than proportional, 2 if proportional and 3 if more than proportional. 'Largely public/largely private/entirely private provision' takes the value 1 if the corresponding response was given in Question 1 of Part B (tax version) and 0 if not. See Table 3 for the definitions of the remaining variables. Significance at the $10 \%, 5 \%$ and $1 \%$ level is denoted by $* * *$ and $* * *$, respectively. 


\section{Questionnaire}

This brief questionnaire contains questions to which we ask you to respond as subjectively as possible. Please read the questions carefully and remember that there are no "right" answers: we are interested in your view! Your responses will help to shed some light upon issues on which scholars and policymakers currently debate.

The questionnaire is anonymous. We would like to thank you very much for your participation.

\section{Part A - Well-being}

Adam, Bob, Chris, Dan and Edward are individuals identical in everything other than their monthly incomes. Adam earns 3,600 Rand. Due to some circumstance, he loses 360 Rand. This loss of money obviously causes Adam's well-being to decrease. What amount of money would Bob, Chris, Dan and Edward have to lose to incur the same reduction in well-being as Adam?

Bob, who earns 1,800 Rand:

$\begin{array}{llllll}\square 18 & \square 90 & \square 162 & \square 720 & \square 1,440 & \\ \square 36 & \square 108 & \square 180 & \square 900 & \square 1,620 & \square \text { other amount : } \\ \square 54 & \square 126 & \square 360 & \square 1,080 & \square 1,800 & \\ \square 72 & \square 144 & \square 540 & \square 1,260 & \square 2,700 & \ldots \ldots \ldots\end{array}$

Chris, who earns 900 Rand:

$\begin{array}{llllll}\square 18 & \square 90 & \square 162 & \square 720 & \square 1,440 & \\ \square 36 & \square 108 & \square 180 & \square 900 & \square 1,620 & \square \text { other amount : } \\ \square 54 & \square 126 & \square 360 & \square 1,080 & \square 1,800 & \ldots \ldots \\ \square 72 & \square 144 & \square 540 & \square 1,260 & \square 2,700 & \ldots \ldots\end{array}$

Dan, who earns 9,000 Rand:

$\begin{array}{llllll}\square 18 & \square 90 & \square 162 & \square 720 & \square 1,440 & \\ \square 36 & \square 108 & \square 180 & \square 900 & \square 1,620 & \square \text { other amount : } \\ \square 54 & \square 126 & \square 360 & \square 1,080 & \square 1,800 & \\ \square 72 & \square 144 & \square 540 & \square 1,260 & \square 2,700 & \ldots \ldots \ldots\end{array}$

Edward, who earns 18,000 Rand:

$\begin{array}{llllll}\square 18 & \square 90 & \square 162 & \square 720 & \square 1,440 & \\ \square 36 & \square 108 & \square 180 & \square 900 & \square 1,620 & \square \text { other amount : } \\ \square 54 & \square 126 & \square 360 & \square 1,080 & \square 1,800 & \ldots \ldots \ldots \\ \square 72 & \square 144 & \square 540 & \square 1,260 & \square 2,700 & \ldots \ldots\end{array}$




\section{Part B - Fines}

In the following two questions we are interested in your opinion concerning fair fines. Please imagine you are in charge of setting up the fines regulations.

Question 1. The imposition of fines is generally justified on two counts: on the one hand, fines are a punishment for having broken the rules; on the other, fines are a deterrent that should induce people not to break the rules. Which of those two motivations do you see as the most important in justifying fines?

$\square$ Punishment $\quad \square$ Deterrent

Question 2. Alan earns 3,600 Rand per month. He has to pay a fine of 360 Rand for speeding. Bill earns 1800 Rand per month and has driven equally fast as Alan. What fine for Bill would your regulation establish?

a) A fine equal to 360 Rand.

b) A fine lower than 360 Rand. I would say ........ (please indicate).

c) A fine larger than 360 Rand. I would say ........ (please indicate).

\section{Part C}

Finally, we would like to ask you a few questions about yourself.
1) Age $: \ldots \ldots \ldots$
2) Sex :
$\square$ Female
Male

3) In which year are you enrolled? $\quad \square 1 \quad \square 2 \quad \square 3 \quad \square 4 \quad \square$ other :......

4) How would you evaluate the current income of your family?
$\square$ very low
low
sufficient
$\square$ high
very high

5) How would you compare the standard of living of your family with that of other families in your country?
very much lower
lower
$\square$ average
higher
very much higher

6) How would you evaluate your expected income five years after you graduate in comparison to that of the other people in your country?

$\square$ very much lower $\quad \square$ lower $\quad \square$ average $\quad \square$ higher $\quad \square$ very much higher

7) Would you say that you and your family have ever experienced material hardship?

$$
\square \text { never } \square \text { rarely } \square \text { frequently } \square \text { very often } \square \text { all the time }
$$

7) Which political party would you vote if elections were tomorrow? .......

8) How would you define your political views?
extreme left
left
centre-left
centre
centre-right
$\square$ right
extreme

right 


\section{Questionnaire}

This brief questionnaire contains questions to which we ask you to respond as subjectively as possible. Please read the questions carefully and remember that there are no "right" answers: we are interested in your view! Your responses will help to shed some light upon issues on which scholars and policymakers currently debate.

The questionnaire is anonymous. We would like to thank you very much for your participation.

\section{Part A - Well-being}

Adam, Bob, Chris, Dan and Edward are individuals identical in everything other than their monthly incomes. Adam earns 3,600 Rand. Due to some circumstance, he loses 360 Rand. This loss of money obviously causes Adam's well-being to decrease. What amount of money would Bob, Chris, Dan and Edward have to lose to incur the same reduction in well-being as Adam?

Bob, who earns 1,800 Rand:

$\begin{array}{llllll}\square 18 & \square 90 & \square 162 & \square 720 & \square 1,440 & \\ \square 36 & \square 108 & \square 180 & \square 900 & \square 1,620 & \square \text { other amount : } \\ \square 54 & \square 126 & \square 360 & \square 1,080 & \square 1,800 & \ldots \ldots \\ \square 72 & \square 144 & \square 540 & \square 1,260 & \square 2,700 & \ldots \ldots\end{array}$

Chris, who earns 900 Rand:

$\begin{array}{llllll}\square 18 & \square 90 & \square 162 & \square 720 & \square 1,440 & \\ \square 36 & \square 108 & \square 180 & \square 900 & \square 1,620 & \square \text { other amount : } \\ \square 54 & \square 126 & \square 360 & \square 1,080 & \square 1,800 & \ldots \ldots \\ \square 72 & \square 144 & \square 540 & \square 1,260 & \square 2,700 & \ldots \ldots\end{array}$

Dan, who earns 9,000 Rand:

$\begin{array}{llllll}\square 18 & \square 90 & \square 162 & \square 720 & \square 1,440 & \\ \square 36 & \square 108 & \square 180 & \square 900 & \square 1,620 & \square \text { other amount : } \\ \square 54 & \square 126 & \square 360 & \square 1,080 & \square 1,800 & \ldots \ldots \ldots \\ \square 72 & \square 144 & \square 540 & \square 1,260 & \square 2,700 & \ldots \ldots\end{array}$

Edward, who earns 18,000 Rand:

$\begin{array}{llllll}\square 18 & \square 90 & \square 162 & \square 720 & \square 1,440 & \\ \square 36 & \square 108 & \square 180 & \square 900 & \square 1,620 & \square \text { other amount : } \\ \square 54 & \square 126 & \square 360 & \square 1,080 & \square 1,800 & \\ \square 72 & \square 144 & \square 540 & \square 1,260 & \square 2,700 & \ldots \ldots\end{array}$




\section{Part B - Taxes}

In the following two questions we are interested in your opinion concerning fair taxation. Please imagine you are in charge of setting up the tax system.

Question 1. Some people believe in the role played by the government in the provision of services such as roads, health and education. Other people think that it is better to leave this to the private market. How do you think the provision of such services should be?

$\square$ entirely public $\quad \square$ largely public $\quad \square$ largely private $\square$ entirely private

Question 2. Alan earns 3,600 Rand and has to pay a tax of 360 Rand. Bill earns 1,800 Rand. What tax for Bill would your tax scheme establish?

a) A tax equal to 360 Rand.

b) A tax lower than 360 Rand. I would say ........ (please indicate).

c) A tax larger than 360 Rand. I would say ........ (please indicate).

\section{Part C}

Finally, we would like to ask you a few questions about yourself.
2) Age $: \ldots \ldots \ldots$
2) Sex :
$\square$ Female $\quad \square$ Male

3) In which year are you enrolled? $\square 1 \quad \square 2 \quad \square 3 \quad \square 4 \quad \square$ other :......

4) How would you evaluate the current income of your family?
$\square$ very low
$\square$ low
$\square$ sufficient
$\square$ high
very high

5) How would you compare the standard of living of your family with that of other families in your country?

$\square$ very much lower $\square$ lower $\quad \square$ average $\quad \square$ higher $\quad \square$ very much higher

6) How would you evaluate your expected income five years after you graduate in comparison to that of the other people in your country?

$\square$ very much lower $\quad \square$ lower $\quad \square$ average $\quad \square$ higher $\quad \square$ very much higher

7) Would you say that you and your family have ever experienced material hardship?

$\square$ never $\square$ rarely $\square$ frequently $\square$ very often $\square$ all the time

7) Which political party would you vote if elections were tomorrow? .......

8) How would you define your political views?

$\square$ extreme left $\square$ left $\square$ centre-left $\square$ centre $\square$ centre-right $\square$ right $\square$ extreme right 